\title{
MORPHOLOGY OF THE EXTRAOCULAR MUSCLES (M. BULBI) IN THE PRE-HATCHLING AND POST-HATCHLING AFRICAN BLACK OSTRICHES (STRUTHIO CAMELUS DOMESTICUS L., 1758) (AVES: STRUTHIONIFORMES)
}

\author{
JoAnna KleĆKOWSKa-Nawrot, ${ }^{*}{ }^{*}$ Karolina GoŹDZIEWSKA-HarŁajcZuK, ${ }^{1}$ \\ KAROLINA BARSZCZ ${ }^{2}$ and MACIEJ JANECZEK ${ }^{1}$ \\ 1Department of Biostructure and Animal Physiology, Faculty of Veterinary Medicine, Wroclaw \\ University of Environmental and Life Sciences, Kozuchowska 1/3, 51-631 Wroclaw, Poland \\ ${ }^{2}$ Department of Morphological Sciences, Faculty of Veterinary Medicine, Warsaw University \\ of Life Sciences, 159 Nowoursynowska, 02-776 Warsaw, Poland
}

(Received: July 31, 2017; accepted: October 30, 2017)

\begin{abstract}
The aim of the study was to describe the morphology and the development of the extraocular muscles (EOMs) in the pre-hatchling and post-hatchling African black ostrich. The study involved 50 birds aged between 28 days and 3 years. The EOMs were analyzed morphologically with respect to the location and length of the straight and oblique muscles and the third eyelid muscles, the length and breadth of their tendons as well as the distance and shape of the muscle tendon insertions at the corneal limbus. A histological and histometric analysis were also carried out. The greatest increase in the length of the EOMs was noted in groups III-V. A marked increase in the length of the tendons of the dorsal straight muscle was found in groups II and III, in the tendons of the nasal straight muscle in groups IV and V, in the tendons of the dorsal oblique muscle in groups III to $\mathrm{V}$ and in the tendons of the ventral oblique muscle in groups IV and V. There was a significant increase in the breadth of the dorsal straight and ventral oblique muscle tendons in groups IV and V and the tendons of the pyramidal muscle in groups III and V. The distance of the distal insertion of the tendon at the corneal limbus increased steadily with age in all the examined groups. The number of fascicles and muscle fibres, their diameter and length in all the studied EOMs were different in the different groups.
\end{abstract}

Keywords: Extraocular muscles - morphology - development - African black ostrich - Struthio camelus domesticus

\section{INTRODUCTION}

Extraocular muscles (EOMs) are accessory organs of the eye (organa oculi accessoria) located between the wall of the orbit and the sclera. The EOMs in birds comprise the dorsal straight ( $m$. rectus dorsalis), ventral straight ( $m$. rectus ventralis), nasal straight ( $m$. rectus nasalis), temporal straight ( $m$. rectus temporalis), dorsal oblique ( $m$. obliquus dorsalis) and ventral oblique (m. obliquus ventralis) muscles and two muscles associated with the movement of the nictitating membrane - the quadratus third eyelid (m. quadratus membranae nictitans) and pyramidal third eyelid muscles

\footnotetext{
*Corresponding author; e-mail address: lestat_v@poczta.onet.pl
} 
(m. pyramidalis membranae nictitans) [26]. Birds do not possess a retractor bulbi muscle $[21,24,26]$. Despite the fact that the EOMs are more fundamental in mammals than in birds, they are tightly wrapped around the eye in birds. When comparing the ratios of eyeball size and muscle size, EOMs are smaller in birds than in mammals. In addition, the avian eyeball is fixed within a large orbit, and ocular motility is more limited in birds than in mammals. Therefore, in birds, the articulation between the head and the spine consists of a single occipital condyle, which allows increased mobility of the atlas and compensates for the limited eye mobility and smaller EOMs compared to mammals $[3,26]$.

Studies of the EOMs have been carried out in chicken, duck, pigeon (Columba livia), tree sparrow (Passer montanus L.), barn owl (Tyto alba), great horned owl (Bubo virginians), red-tailed hawk (Buteo jamaicensis) and Harris hawk (Parabuteo unicinctus) and were focused mainly on the physiology of those muscles, rather than their morphology and development [1, 2, 4, 14, 25, 28].

This study was focused on the morphological and histological analysis of the EOMs in the African black ostrich in the embryonic and postnatal period and was performed to contribute to the current knowledge of the comparative anatomy of domestic, ornamental and wild birds. Data on the development, location, length and breadth of the EOMs, the distance of the tendon insertions from the corneal limbus as well as the line of insertions are provided. Another aim of the study was to describe the growth of EOMs of different age groups of birds (from the pre-hatchling period to adult birds). To date, there have been no studies on the development and the morphology of the EOMs in the African black ostrich. In birds, the eye is the most important sense organ, and its proper functioning depends on the correct structure of the eyeball and accessory organs of the eye, including the EOMs. Any conformational or functional defects of the EOMs may affect eyesight, influencing the functioning of the African black ostrich and the quality and quantity of the animal products (especially meat, eggs and feathers) [12]. Diseases affecting the eyes and the muscles negatively affect homeostasis causing weight loss, reproductive disorders and the quantity of eggs laid. Owing to the growing number of ostrich farms, there is a need for specialized veterinary care. Veterinary specialists are expected to have advanced knowledge of the physiological structure of the eye and eye diseases in those animals. Our study may contribute to the diagnosis and treatment of ocular diseases in domestic, wild and ornamental (including cage) birds.

\section{MATERIAL AND METHODS}

\section{Animals}

The study was performed on 50 African black (Struthio camelus domesticus) ostriches aged between 28 days of incubation and 3 years of age. The study was carried out on 10 pre-hatchling birds ( 28 and 40 days of incubation) and 40 post-hatchling birds (24, 72 hours after hatching; 2, 8 weeks old; 3, 6 and 20 months old and 3 years old). 
The animals were divided into five age groups based on their histological differences: group I - incubation stages ( 28 and 40 days of incubation); group II - birds directly after hatching $(24,72$ hours after hatching); group III - very young birds $(2,8$ weeks old); group IV - young birds ( 3 and 6 months old); group V - adult birds (20 months and 3 years old). The eggs were incubated for a total of 42 days. The embryos were provided by an ostrich farm in Namyslow, Poland. The extracted embryos were classified according to the different developmental stages, based on the days of incubation. Post-hatchling birds from the ostrich farm in Namyslow hatched from 2010 to 2011. None of the birds enrolled in the study received intraocular vaccinations. All the birds that died did so as a result of natural causes. Mummified or underdeveloped embryos and nestlings were eliminated from the study. The EOMs were dissected from the embryos and the birds immediately after death. They were then fixed in $4 \%$ buffered formaldehyde for 48 hours. The study was approved by the II Local Ethics Committee in Wroclaw (no. 19/2010).

\section{Macroscopic evaluation}

The macroscopic evaluation of the EOMs was performed under a stereoscopic Zeiss Stemi 2000-C microscope (Carl Zeiss, Jena, Germany). A 0.5-4\% solution of acetic acid and $70 \%$ ethyl alcohol were used to clearly present the anatomical structure of the EOMs. Holotopic and syntopic descriptions of the EOMs were also carried out. The examinations were conducted using a magnifying glass $(4.5 \times)$ and a Zeiss Stemi 2000-C stereoscopic microscope (Carl Zeiss, Jena, Germany). Morphometric measurements (the EOM length, the length and the width of the EOM tendons - Hifny and Misk's method [6-10]) were conducted using an electronic slide caliper with an accuracy of $0.1 \mathrm{~mm}$. The method was applied to measure the distance of the distal insertions of the muscle tendons in the corneal limbus. The dorsal straight, ventral straight, nasal straight, temporal straight, dorsal oblique, ventral oblique, quadratus third eyelid and pyramidal third eyelid muscles were assessed morphologically. All the anatomical terminology used in the results sections is in accordance with the Nomina Anatomica Avium [26].

\section{Histological analysis}

The dorsal straight, ventral straight, nasal straight, temporal straight, dorsal oblique, ventral oblique, quadratus third eyelid and pyramidal third eyelid muscles were analysed histologically. Dissected EOMs were directly fixed in $4 \%$ buffered formaldehyde for 48 hours. The EOMs were then rinsed under running water for $24 \mathrm{~h}$, processed in an ETP (RVG3, Intelsint, Italy) vacuum tissue processor, embedded in paraffin and cut into 3-4 $\mu \mathrm{m}$ sections on a sliding microtome Slide 2003 (Pfm A.g., Germany). All the samples were stained using hematoxylin and eosin and MassonGoldner trichrome. The histological slides were examined under a Zeiss Axio Scope. 
A1 light microscope (Carl Zeiss, Jena, Germany). The length of the muscle fibres was calculated on the basis of the thickness of the section of each fascicle. The diameter of the fascicles in the equatorial region and the diameter of the muscle fibres were also measured. Data were statistically analysed and values are expressed as mean \pm standard deviation.

\section{RESULTS}

\section{Macroscopic study}

\section{Dorsal straight muscle}

The dorsal straight muscle extended from the common tendinous ring to the distal insertion situated on the sclera posteriorly from the corneal limbus. It was present in the mediolateral axis along with the levator muscle of the upper eyelid and passed over the ligament of the dorsal oblique muscle. The dorsal straight muscle ran above the quadratus muscle of the third eyelid (Fig. 1).

The morphometric examinations showed clear differences in the tendon breadth, tendon length and the length of the dorsal straight muscle among the studied groups of birds (Figs 2a-2c). The largest increase in the length of the dorsal straight muscle and the breadth of its tendon was observed between groups IV and V. The largest increase in the tendon length was observed between groups II and III. The difference in the tendon length between groups III and V increased much more steadily. The length of the tendon increased the most between groups II and III. That increase was steady between groups III and V. A similar relationship was observed in terms of the distance of the distal insertion of the tendon to the corneal limbus, which grew linearly with age in all the examined groups (Fig. 2d). The distal insertion line of the dorsal straight muscle tendon was convex in shape.

\section{Ventral straight muscle}

The ventral straight muscle emerged from the common tendinous ring and entered the sclera, anterior to the equator of the globe, ran in the mediolateral axis, and was covered by the belly of the ventral oblique muscle. The ventral straight muscle covered the pyramidal muscle of the third eyelid and the tendon of the pyramidal muscle (Fig. 1). The morphometric examination also showed significant differences in the length of the ventral rectus muscle as well as the length and breadth of its tendon among the studied groups of birds (Figs 2a-2c).

The growth rate was steady in all the groups of birds. The distance of the distal insertion of the tendon to the corneal limbus grew linearly with age in all the examined groups (Fig. 2d). The distal insertion line of the ventral straight muscle tendon was convex. 


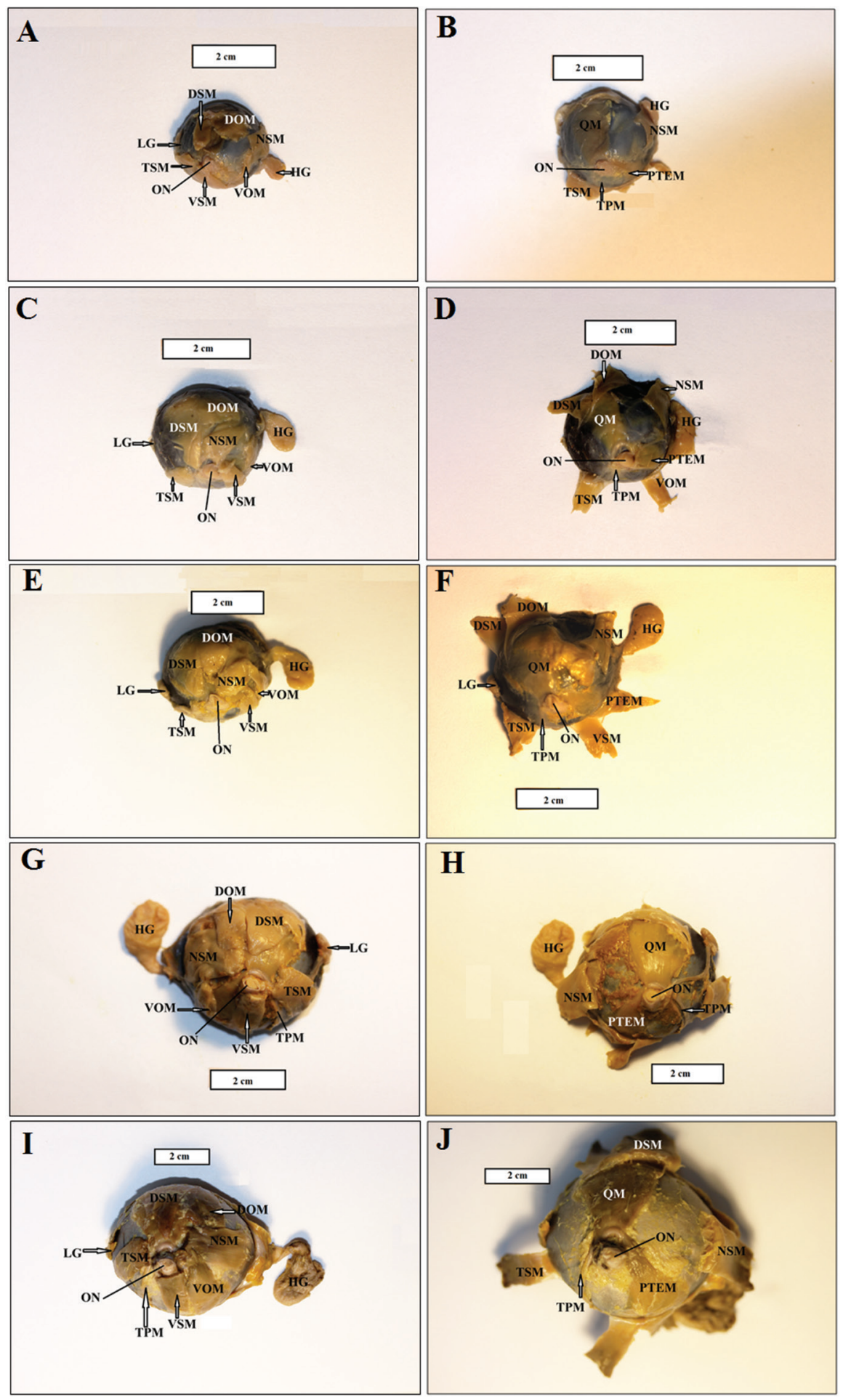


Fig. 1. The EOMs of the African black ostrich. A, B - group I; C, D - group II; E, F - group III; G, H - group IV; I, J - group V. Bar $=2 \mathrm{~cm}$. DSM - dorsal straight muscle, NSM - nasal straight muscle, TSM - temporal straight muscle, VSM - ventral straight muscle, DOM - dorsal oblique muscle, VOM - ventral oblique muscle, QM - quadratus muscle, PTEM - pyramidal third eyelid muscle, TPM - tendo pyramidal muscle, $\mathrm{ON}$ - optic nerve

\section{Nasal straight muscle}

The nasal straight muscle ran in the vertical axis along the medial side on the eyeball, between the dorsal and the ventral straight muscles. The nasal straight muscle ran from the common tendinous ring to the sclera, where it attached anteriorly to the equator of the globe (Fig. 1). The morphometric examination showed clear differences in the length of the nasal straight muscle and the length and breadth of its tendon between the studied groups of birds (Figs 2a-2c). The largest increase in the length of the muscle was found between groups III, IV and V. The increase in the length of the tendon was steady between groups I and III, while it differed significantly between groups IV and V. The breadth of the tendon and the distance of the distal insertion site of the tendon in the corneal limbus increased linearly with age in all the examined groups (Fig. 2d). The distal insertion line of the nasal straight muscle tendon was oblique.

\section{Temporal straight muscle}

The temporal straight muscle originated in the common tendinous ring and ran to the sclera, where it attached behind the equator of the globe. The temporal straight muscle ran in the vertical axis along the lateral side of the eyeball, between the dorsal and ventral straight muscles. The temporal straight muscle covered the tendon of the pyramidal muscle and reached the Harderian gland (Fig. 1). The morphometric examination showed significant differences in the length of the temporal straight muscle and the length and breadth of the tendon among the study groups (Figs $2 \mathrm{a}-2 \mathrm{c})$. The most significant difference in the muscle length was found between groups III and IV. The length and breadth of the tendon as well as the distance of the distal insertion of the tendon in the corneal limbus increased steadily with age in all the examined groups (Fig. 2d). The distal insertion line of the temporal straight muscle tendon was oblique.

\section{Dorsal oblique muscle}

The dorsal oblique muscle originated in the dorsomedial margin of the interorbital septum and ran below the tendon of the dorsal straight muscle on the dorsolateral surface of the globe. The dorsal oblique muscle covered the quadratus muscle 
(Fig. 1). The morphometric examination showed marked differences in the length of the dorsal oblique muscle and the length and breadth of its tendon among the studied groups of birds (Figs 2a-2c). The largest difference in the length of the muscle was observed between groups IV and V, while groups III, IV and V showed the largest difference in the length of its tendon. Such differences were not found in straight muscles. The breadth of the tendon and the distance of the distal insertion of the tendon at the corneal limbus increased linearly, similarly to the straight muscles (Fig. 2d). The distal insertion line of the dorsal oblique muscle tendon was oblique.

\section{Ventral oblique muscle}

The ventral oblique muscle ran from the interorbital septum, above the tendon of the ventral straight muscle and attached to the ventrolateral surface of the globe. It ran parallel with the pyramidal muscles of the third eyelid (Fig. 1). The morphometric examination showed significant differences in the length of the ventral oblique muscle and the length and breadth of its tendon among the studied groups of ostriches (Figs 2a-2c). The most significant differences in the muscle length were found between groups III, IV and V, while the largest differences in the breadth of its tendon were found between groups IV and V. The length of the tendon and the distance of the distal insertion of the tendon at the corneal limbus increased steadily with age in all the examined groups (Fig. 2d). The distal insertion line of the ventral oblique muscle tendon was oblique.

\section{Quadratus muscle}

The quadratus muscle was located on the postero-dorsal surface of the globe. It ran below the dorsal oblique and dorsal straight muscles and reached the dorsal side of the optic nerve, where it formed a loop, through which the tendons of the pyramidal muscle passed (Fig. 1). The morphometric examination showed significant differences in the length of the quadratus muscle and the breadth of its tendons among the studied groups (Figs 2a-2c). A large increase in the length of the muscle was found in groups III, IV and V. There were no statistically significant differences in the length of the tendon among the groups. There was a significant increase in the breadth of the tendon in all the groups. The distance of the distal insertion of the tendon at the corneal limbus increased steadily with age in all the examined groups (Fig. 2d). The distal insertion line of the quadratus muscle tendon was convex.

\section{Pyramidal muscle}

The pyramidal muscle was located on the postero-ventral surface of the globe. It was covered by the ventral straight and ventral oblique muscles. Its tendon passed through 


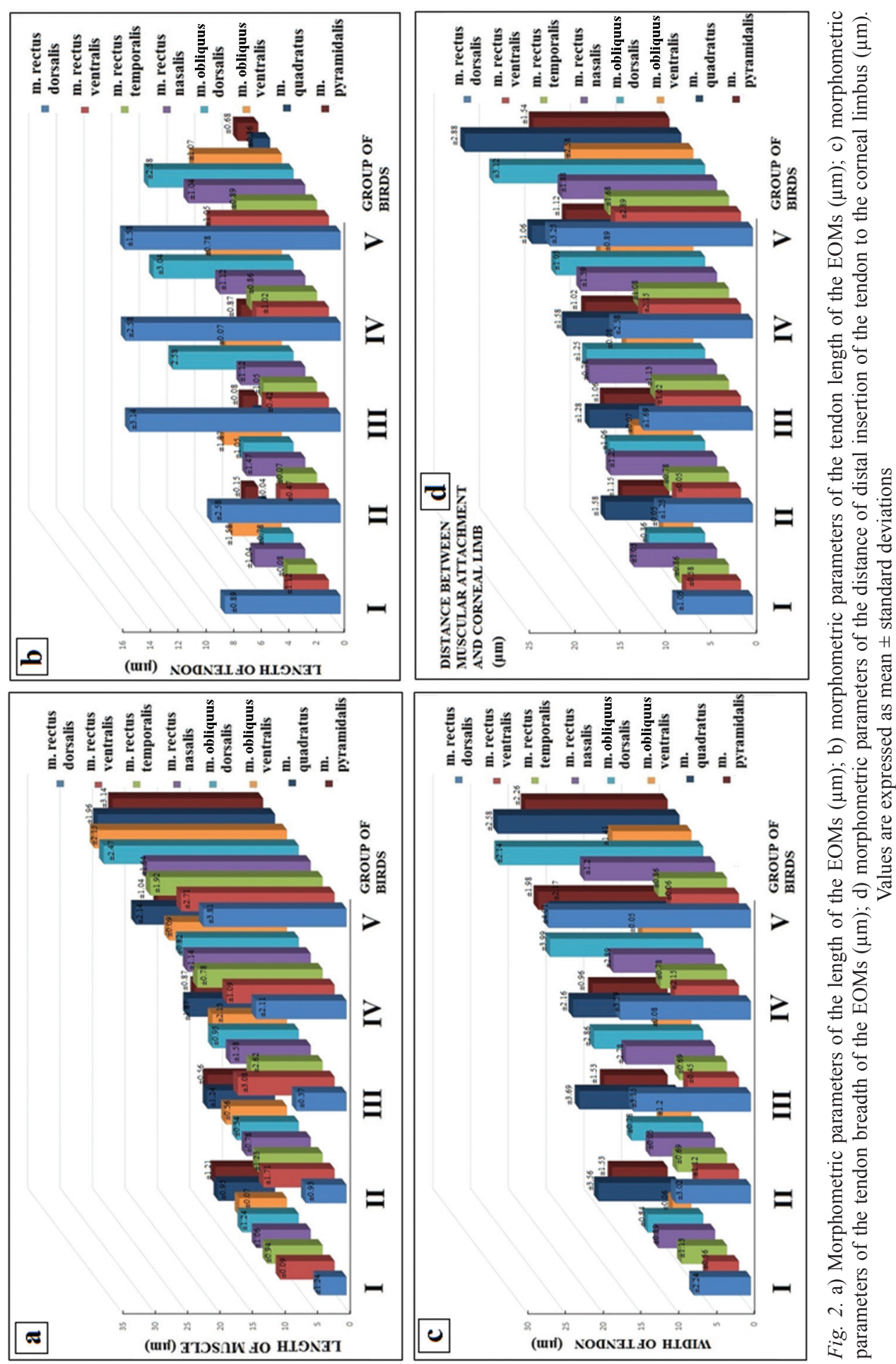



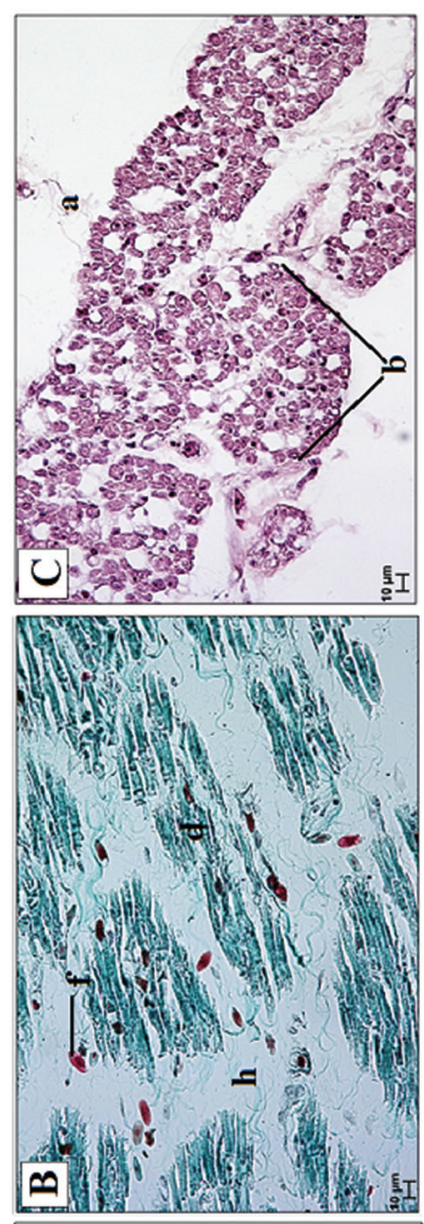

!⿱
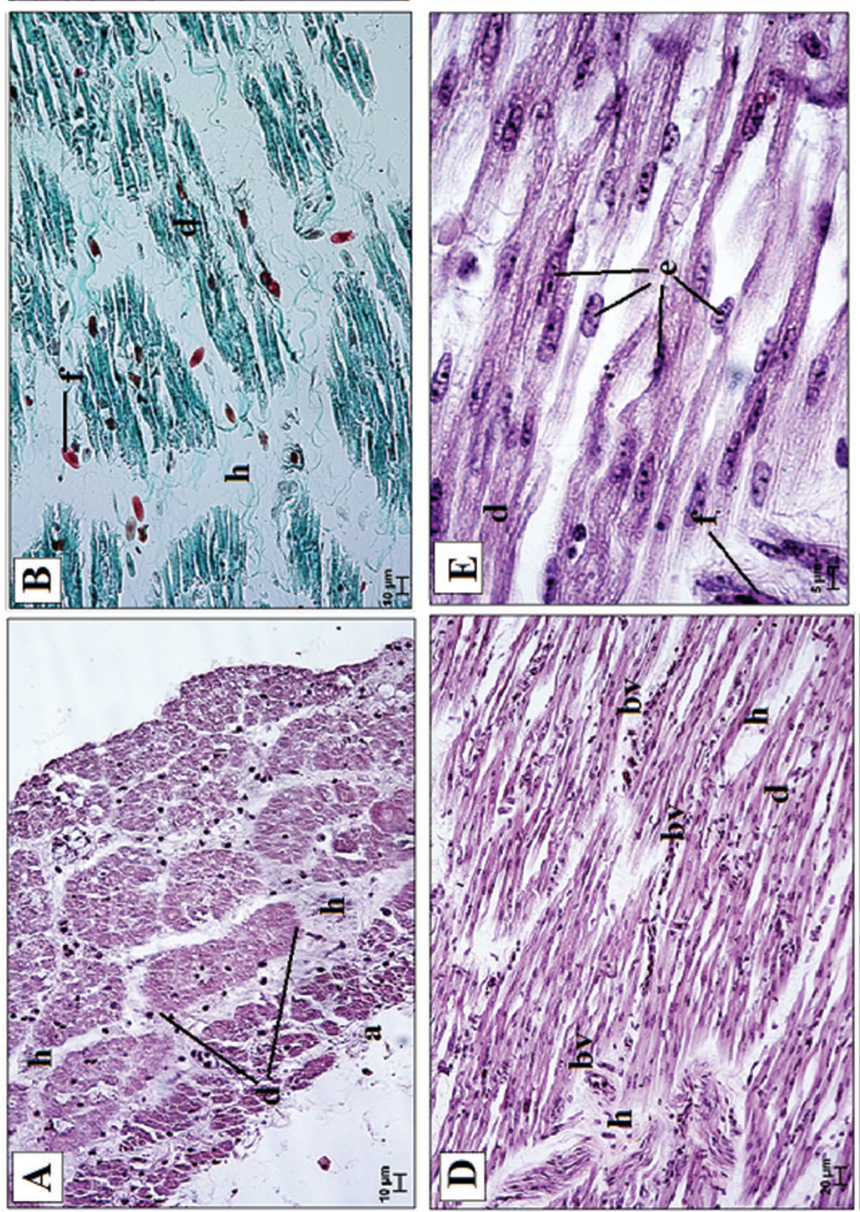

홍동

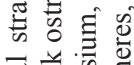

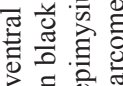

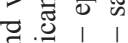

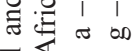

跑㟔官产

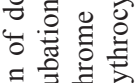

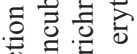

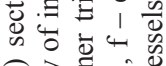

(c) $\overrightarrow{\mathrm{E}}$

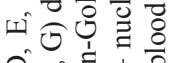

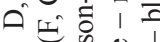

ขㄷำ

ส․ $\Xi \frac{0}{0}$ ह

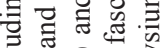

당ำ

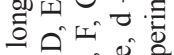

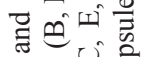

조의 응

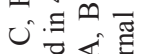

过过

问.

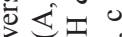

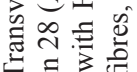

ni 0

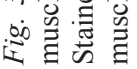

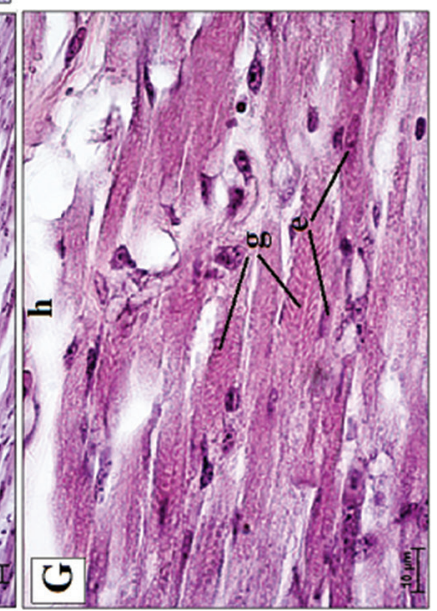

Acta Biologica Hungarica 69, 2018 
the loop created by the quadratus muscle (Fig. 1). The morphometric examination showed significant differences in the length of the pyramidal muscle and the length and breadth of its tendon between the studied groups of birds (Figs 2a-2c). A large difference in the length of the muscle between groups III, IV and V was observed. There was a significant increase in the breadth of the tendon between groups III and IV. There were no statistically significant differences in the length of the tendon of that muscle. The distance of the distal insertion of the tendon at the corneal limbus grew linearly with age in all the examined groups (Fig. 2d). The distal insertion line of the pyramidal muscle tendon was wavy.

\section{Histological and histometric analysis}

The straight, oblique and third eyelid muscles were enclosed in the epimysium, a connective tissue sheath, which surrounded the muscle mass (Figs 3-4). Connective tissue septa emerged from the deeper layers of this sheath - perimysium. There were numerous blood vessels within the perimysium in all the studied groups of birds (Figs 3-4). In group I, the muscle fascicles were small and enclosed in a thin layer of perimysium (Fig. 3). The fascicles were larger, and the perimysium increased in thickness in groups II to V (Figs 3-4). The external capsule was visible in groups III-V (Fig. 4). A distinct space was visible between the capsule and the fascicles. Transverse striation was seen in group II (Fig. 3). The total number of fascicles in the dorsal straight muscle varied from 39 in group I to 45 in group $\mathrm{V}$ (Table 1). In the ventral straight muscle, this number varied from 41 in group I to 56 in group $\mathrm{V}$ (Table 1). In the case of the nasal straight muscle, it rose from 31 in group I to 69 in group V (Table 1). The total number of fascicles varied from 58 in group I to 77 in group $\mathrm{V}$ in the temporal straight muscle (Table 1). The length of the muscle fibres differed among the age groups, and ranged from $65-612 \mu \mathrm{m}$ in the dorsal straight muscle, 103-714 $\mu \mathrm{m}$ in the temporal straight muscle, 123-721 $\mu \mathrm{m}$ in the temporal straight muscle to $167-645 \mu \mathrm{m}$ in the nasal straight muscle (Table 1). With advancement diameters of the muscle fascicles increased from 57 to $198 \mu \mathrm{m}$ and the diameters of the muscle fibers increased from 7 to $87 \mu \mathrm{m}$ (Table 1). Similar findings were made in the oblique and third eyelid muscles. The total number of muscle fascicles varied from 41 in group I to 66 in group $\mathrm{V}$ in the dorsal oblique muscle, from 32 in group I to 69 in group $\mathrm{V}$ in the ventral oblique muscle, from 42 in group I to 71 in group $\mathrm{V}$ in the quadratus muscle and from 35 in group I to 70 in group $\mathrm{V}$ in the pyramidal muscle (Table 2). The length of the muscle fibers differed in the developmental groups. It ranged from 67 to $398 \mu \mathrm{m}$ in the dorsal oblique muscle, 55 to 404 $\mu \mathrm{m}$ in the ventral oblique muscle, 67 to $405 \mu \mathrm{m}$ in the quadratus muscle and 57 to $454 \mu \mathrm{m}$ in the pyramidal muscle (Table 2 and Table 3). With advancement, the diameters of the fascicles increased from 58 to $189 \mu \mathrm{m}$ in the oblique muscles and from 58 to $278 \mu \mathrm{m}$ in the third eyelid muscles (Table 2 and Table 3 ). The diameters of the muscle fibers increased from 7 to $39 \mu \mathrm{m}$ in the oblique muscle and from 7 to $41 \mu \mathrm{m}$ in the third eyelid muscles (Table 2 and Table 3 ). The histological analysis revealed 


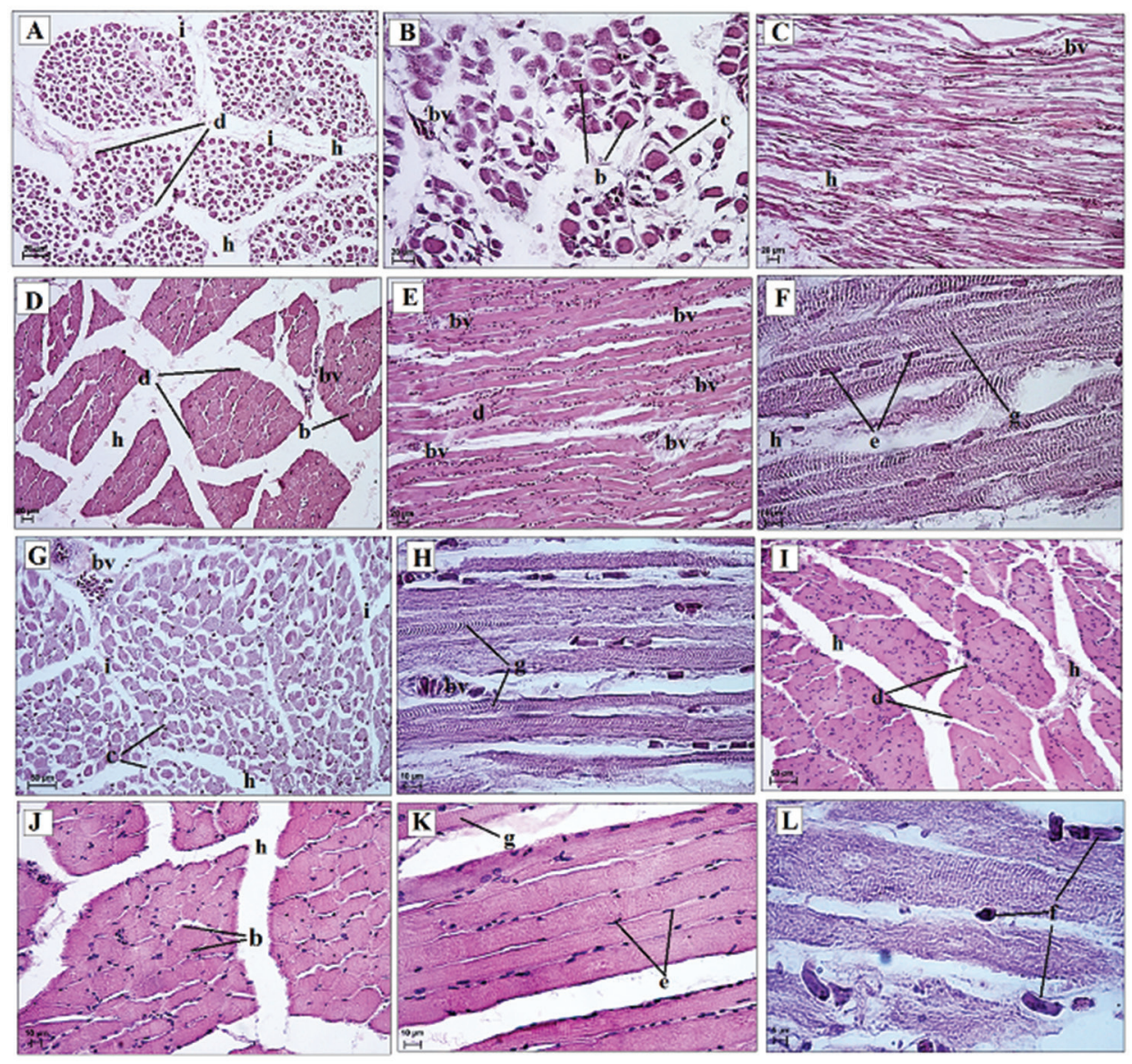

Fig. 4. Transverse (A, C, D, G, J) and longitudinal (B, D, C, E, F, H, K, L) sections of the dorsal and ventral oblique muscles in the $2(\mathrm{~A}, \mathrm{C})$ and $8(\mathrm{~B})$ week of life; in the $3(\mathrm{D})$ and $6(\mathrm{E}, \mathrm{F})$ month of life; in the 20 month of life $(\mathrm{G}, \mathrm{H})$ and in the 3 years old $(\mathrm{I}, \mathrm{J}, \mathrm{K}, \mathrm{L})$ of African black ostrich. Stained with $\mathrm{H}, \mathrm{E}$. $\mathrm{b}$ - muscle fibres, $\mathrm{c}$ - internal capsule, $\mathrm{d}$ - fascicle, $\mathrm{e}$ - nuclei, $\mathrm{f}$ - erythrocytes, $\mathrm{g}$ - sarcomeres, $\mathrm{h}$ - perimysium, i - internal capsule, bv - blood vessels

the presence of three types of fibers in the EOMs in the African black ostriches in groups IV and V. In those groups, second and third types of fibres predominated. Such fibers were not found in the specimens in groups I to III. All the muscle fibres were found throughout the whole length of the straight, oblique and third eyelid muscles, but they were located more frequently in the proximal and distal portions of each muscle. 
Table 1

The histometry of the straight muscle in African black ostrich

\begin{tabular}{|c|c|c|c|c|c|}
\hline Group & $\begin{array}{l}\text { Investigated } \\
\text { muscle }\end{array}$ & $\begin{array}{l}\text { Number } \\
\text { of fascicles }\end{array}$ & $\begin{array}{c}\text { Diameter } \\
\text { of fascicle }(\mu \mathrm{m})\end{array}$ & $\begin{array}{c}\text { Length } \\
\text { of the muscle fibers } \\
(\mu \mathrm{m})\end{array}$ & $\begin{array}{c}\text { Diameter } \\
\text { of muscle fibres } \\
(\mu \mathrm{m})\end{array}$ \\
\hline I & $\begin{array}{c}\text { dorsal } \\
\text { ventral } \\
\text { temporal } \\
\text { nasal }\end{array}$ & $\begin{array}{l}39 \\
46 \\
58 \\
31\end{array}$ & $\begin{array}{l}57-59 \\
51-82 \\
57-77 \\
46-51\end{array}$ & $\begin{array}{c}65-85 \\
103-142 \\
123-155 \\
167-177\end{array}$ & $\begin{array}{l}7-27 \\
7-58 \\
5-43 \\
9-58\end{array}$ \\
\hline II & $\begin{array}{c}\text { dorsal } \\
\text { ventral } \\
\text { temporal } \\
\text { nasal }\end{array}$ & $\begin{array}{l}41 \\
48 \\
61 \\
42\end{array}$ & $\begin{array}{l}60-63 \\
55-83 \\
60-81 \\
47-63\end{array}$ & $\begin{array}{c}68-88 \\
108-149 \\
131-158 \\
168-181\end{array}$ & $\begin{array}{c}8-29 \\
8-61 \\
10-52 \\
10-64\end{array}$ \\
\hline III & $\begin{array}{c}\text { dorsal } \\
\text { ventral } \\
\text { temporal } \\
\text { nasal }\end{array}$ & $\begin{array}{l}44 \\
48 \\
67 \\
58\end{array}$ & $\begin{array}{l}115-146 \\
126-134 \\
112-161 \\
103-166 \\
\end{array}$ & $\begin{array}{l}529-582 \\
592-598 \\
606-686 \\
587-601 \\
\end{array}$ & $\begin{array}{l}21-35 \\
23-36 \\
30-59 \\
27-66 \\
\end{array}$ \\
\hline IV & $\begin{array}{c}\text { dorsal } \\
\text { ventral } \\
\text { temporal } \\
\text { nasal }\end{array}$ & $\begin{array}{l}44 \\
49 \\
69 \\
66\end{array}$ & $\begin{array}{l}142-167 \\
163-176 \\
154-178 \\
124-186\end{array}$ & $\begin{array}{l}535-587 \\
593-602 \\
606-697 \\
587-623\end{array}$ & $\begin{array}{l}20-37 \\
24-36 \\
33-61 \\
28-76\end{array}$ \\
\hline V & $\begin{array}{c}\text { dorsal } \\
\text { ventral } \\
\text { temporal } \\
\text { nasal }\end{array}$ & $\begin{array}{l}45 \\
56 \\
77 \\
69\end{array}$ & $\begin{array}{l}179-185 \\
201-231 \\
198-204 \\
157-198\end{array}$ & $\begin{array}{l}587-612 \\
604-714 \\
638-721 \\
597-645\end{array}$ & $\begin{array}{l}20-54 \\
26-46 \\
41-77 \\
37-87\end{array}$ \\
\hline
\end{tabular}

Table 2

The histometry of the oblique muscle in African black ostrich

\begin{tabular}{|c|c|c|c|c|c|}
\hline Group & $\begin{array}{c}\text { Investigated } \\
\text { muscle }\end{array}$ & $\begin{array}{c}\text { Number } \\
\text { of fascicles }\end{array}$ & $\begin{array}{c}\text { Diameter } \\
\text { of fascicle }(\mu \mathrm{m})\end{array}$ & $\begin{array}{c}\text { Length } \\
\text { of the muscle } \\
\text { fibres }(\mu \mathrm{m})\end{array}$ & $\begin{array}{c}\text { Diameter of muscle } \\
\text { fibres }(\mu \mathrm{m})\end{array}$ \\
\hline \multirow{2}{*}{ I } & dorsal & 41 & $58-62$ & $67-74$ & $7-16$ \\
& ventral & 32 & $48-53$ & $55-56$ & $7-10$ \\
\hline \multirow{2}{*}{ II } & dorsal & 42 & $59-63$ & $77-89$ & $8-20$ \\
& ventral & 36 & $48-58$ & $67-82$ & $8-24$ \\
\hline \multirow{2}{*}{ III } & dorsal & 44 & $89-101$ & $98-132$ & $14-27$ \\
& ventral & 37 & $88-98$ & $101-145$ & $17-28$ \\
\hline \multirow{2}{*}{ IV } & dorsal & 56 & $121-129$ & $184-275$ & $21-32$ \\
& ventral & 49 & $132-145$ & $287-326$ & $25-33$ \\
\hline \multirow{2}{*}{ V } & dorsal & 66 & $145-187$ & $315-398$ & $25-38$ \\
& ventral & 69 & $167-189$ & $387-404$ & $25-39$ \\
\hline
\end{tabular}


Table 3

The histometry of the third eyelid muscle in African black ostrich

\begin{tabular}{|c|c|c|c|c|c|}
\hline Group & $\begin{array}{c}\text { Investigated } \\
\text { muscle }\end{array}$ & $\begin{array}{c}\text { Number } \\
\text { of fascicles }\end{array}$ & $\begin{array}{c}\text { Diameter } \\
\text { of fascicle }(\mu \mathrm{m})\end{array}$ & $\begin{array}{c}\text { Length } \\
\text { of the muscle } \\
\text { fibres }(\mu \mathrm{m})\end{array}$ & $\begin{array}{c}\text { Diameter } \\
\text { of muscle fibres } \\
(\mu \mathrm{m})\end{array}$ \\
\hline \multirow{2}{*}{ I } & quadratus & 42 & $58-71$ & $67-75$ & $7-15$ \\
& pyramidal & 35 & $45-56$ & $57-62$ & $6-10$ \\
\hline \multirow{2}{*}{ II } & quadratus & 44 & $61-63$ & $79-93$ & $8-24$ \\
& pyramidal & 38 & $46-57$ & $69-89$ & $8-28$ \\
\hline \multirow{2}{*}{ III } & quadratus & 45 & $86-112$ & $102-137$ & $15-26$ \\
& pyramidal & 39 & $89-121$ & $145-165$ & $15-28$ \\
\hline \multirow{2}{*}{ IV } & quadratus & 57 & $132-142$ & $189-263$ & $23-34$ \\
& pyramidal & 44 & $116-165$ & $267-378$ & $27-33$ \\
\hline \multirow{2}{*}{ V } & quadratus & 71 & $187-228$ & $337-405$ & $26-39$ \\
& pyramidal & 70 & $197-278$ & $389-454$ & $26-41$ \\
\hline
\end{tabular}

\section{DISCUSSION}

Most studies concerning the EOMs have been carried out in humans [19, 20, 30, 31]. The findings of these studies are applied in strabismus surgeries and other orbital procedures $[5,11]$.

Several teams have investigated EOMs measurements in humans. Morphometric studies have focused on the length and width of the muscle bellies and muscle tendons, the relative position of the muscles and individual variations. The anatomical variations of the EOMs are of great importance because they must be considered during surgical interventions. The study by Villarreal-Silva et al. [31] on embalmed human cadavers aged between 30 and 60 years revealed that the superior straight and lateral straight muscles were the largest and that the difference in the width between the superior straight and inferior straight muscles was greater than that between the medial straight and lateral straight muscles. Furthermore, the authors found that the point of insertion of the straight muscles varied morphologically. They also found that the width of the superior oblique muscle was smaller in relation to other references and that the morphology of the inferior oblique muscle components was similar to that previously reported. No anatomical variations in the EOMs were found, the study confirmed the presence of two muscles in the third eyelid, which have only been reported in birds, reptiles and amphibians [4, 29]. These muscles determine the movement of the third eyelid. Their presence in the studied African black ostriches indicates that the EOMs have a unique arrangement which is associated with the characteristic cranial structure typical for bird species. The macroscopic studies of the EOMs revealed that the greatest increase in muscle length as well as the tendon length and tendon breadth was found in the straight muscles between groups III, IV and $\mathrm{V}$. The greatest increase in the length of the oblique muscle and the breadth of its tendon was found in groups III-V, while the length of the tendon increased steadily 
in all the groups. The length of the pyramidal muscle and the length of the quadratus muscle differed significantly between groups III and V, while the breadth of the tendon of the pyramidal muscle differed significantly between groups III and IV. The increase in the length of the tendon of both muscles of the third eyelid was steady in all the age groups. The distance of the distal insertion of the tendon in the corneal limbus grew linearly with age in all the examined groups in all the EOMs. In their study on barn owls, great horned owls, red-tailed hawks and Harris hawks, Fraser et al. [4] showed that hawks have larger EOMs than owls, even when considering eye size and body size differences. We also determined the distal insertion line of the rectal and oblique muscles and the muscles of the third eyelid, which were of three shapes (convex, oblique and wavy). Hifny and Misk [6-10] as well as KlećkowskaNawrot [16], Klećkowska and Pospieszny [17], Klećkowska et al. [18] carried out a similar analysis in other animal species and distinguished four shapes of the distal insertion line - convex, concave, oblique and straight. We also measured the distance of the distal insertion of the tendon at the corneal limbus, and found that this distance grew linearly in all the groups.

A study of the superior oblique EOMs in chickens carried out by Baryshnikova et al. [2] showed that the EOM myofiber types largely correspond to their mammalian counterparts, with four fiber types in the orbital layer and four types in the global layer. In the studied chickens, the twitch tension muscle force and muscle mass gradually increased and stabilized at approximately 11 weeks. The authors measured muscle fiber diameters for both the global and orbital layers and found that the EOM fiber diameters relate to the muscle force and muscle mass. Measurements using a light microscope showed an increase in diameter of the superior oblique muscle fibers from just after hatching - 2 days of life to 112 days of age. The orbital myofiber diameters increased from an average of 6.4 to $15.1 \mathrm{~mm}$, while the global myofiber diameters increased from an average of 11.8 to $26.6 \mathrm{~mm}$ during that period. The myofiber diameters in both the orbital and global layers increased from the time of hatching until the animal reached six weeks of age, and then it stabilized, whereas the number of myofibers remained constant after hatching. This finding suggests that myofibers increase in length rather than in thickness to produce larger muscle mass, and possibly muscle force. Muscles force can be augmented by increased myofiber length in skeletal muscles [27] as well as in EOMs [23].

In 2-week-old chickens, the orbital layer contained 81\% type I myofibers, and 19\% type II, III, IV myofibers, while the global layer consisted of type I, II, III, and IV evenly dispersed myofibers. After 11 weeks of age, the global layer of the muscle underwent further compartmentalization, so that the multiply innervated muscle fibers (type IV) were concentrated at the global surface of the muscle. In cross-sections through the mid-belly of the muscle, the global layer was positioned at a distance of $300-400 \mathrm{~mm}$ from the orbital surface, while the singly innervated myofiber types (types I, II, and III) were more evenly distributed within the global layer [2]. Our study carried out in the African black ostrich, from the $28^{\text {th }}$ day of incubation until 3 years of age, assessed all the EOMs and revealed that the muscle fibres were larger and the perimysium increased in thickness in groups II to V. An external capsule was 
visible in group III, while transverse striation was noted from the groups II to V. The number, diameter and length of the muscle fibres as well as the diameter of the fascicles grew linearly with age in all the age groups. Similarly to the study of Maier et al. [22], we found an absence of muscle spindles in the EOMs. The confirmation or contradiction of the presence of muscle spindles in these birds requires immunohistochemical and ultrastructural examinations. Kaczmarski [13] carried out a study on tree sparrows and distinguished three fibre types in the EOMs on the basis of the fibre diameter. Alvarado-Mallart [1] also differentiated three types of fibers in the ventral straight muscle of the pigeon. The first type was similar to mammalian twitch fibers and the two remaining types were: the slow fibers with an M-line which resembled chicken anterior latissimus dorsi fibers and slow fibers with a clear M-line similar to the EOMs of rabbits, rats and rhesus monkeys. Based on their histological studies of animals and humans, Kern [15] described those three types of fibers. In their study, the first type of fibers had few branches and were more or less circular in the transverse section, while the second and third types of fibers possessed more branches and had an irregular outline in the transverse section. Our study revealed the presence of these three types of fibres, which were more abundant than the former fibers, in the EOMs of the African black ostriches in groups IV and V.

The study focused on describing the morphology and development of the EOMs in pre-hatchling and post-hatchling African black ostriches. The results may warrant for further research into the accessory organs of the eye, influencing vision in animals and humans. They may also enable an interrelation of species differences and may contribute to preventive studies.

\section{ACKNOWLEDGEMENTS}

The translation of the publication was supported by the Wroclaw Center of Biotechnology and the 2014-2018 Leading National Research Center (KNOW) program. JKN obtained the research material, performed the study in the departmental laboratory, interpreted the data and edited the manuscript. KGH supervised the research and edited the manuscript. KB edited the manuscript. MJ edited the manuscript.

\section{REFERENCES}

1. Alvarado-Mallart, R. M. (1972) Ultrastructure of muscle muscle fibres of an extraocular of the pigeon. Tiss. Cell 4, 327-339.

2. Baryshnikova, L. M., Croes, S. A., Von Bartheld, C. S. (2007) Classification and development of myofiber types in the superior oblique extraocular muscle of chicken. Anat. Rec. (Hoboken) 290, $1526-1541$

3. Bayon, A., Almela, R. M., Talavera, J. (2007) Avian ophthalmology. Europ. J. Comp. Anim. Prac. $17,1-13$.

4. Fraser, A., Segev, T., Graw, W. A., Suchocki, L., Hall, M. I. (2013) Comparative morphology of owl and hawk extraocular muscles. Society for Integrative and Comparative Biology. Annual Meeting $\mathrm{P} 1,132$.

5. Feng, X., Pilon, K., Yaacobi, Y., Olsen, T. W. (2005) Extraocular muscle insertions relative to the fovea and optic nerve: humans and rhesus macaque. Invest. Ophthal. \& Vis. Sci. 46, 3493-3496. 
6. Hifny, A., Misk, N. A. (1977) The anatomy of the tendons of intersections of the extrinsic muscles of the eyeball in the sheep and goat. As. Vet. Med. J. 4, 11-18.

7. Hifny, A., Misk, N. A. (1977) The anatomy of the tendons of intersections of the extrinsic muscles of the eyeball in the buffalo, cow and camel. Anat. Histol. Embryol. 6, 339-346.

8. Hifny, A., Misk, N. A. (1979) The anatomy of the tendons of intersections of the extrinsic muscles of the eyeball in the pig. XXI World Veterinary Congress, Moscow.

9. Hifny, A., Misk, N. A. (1980) The anatomy of the tendons of intersections of the extrinsic muscles of the eyeball in the donkey, mule and horse. Ass. Vet. Med. J. 7, 201-212.

10. Hifny, A., Misk, N. A. (1982) The anatomy of the tendons of intersections of the extrinsic muscles of the eyeball in different domestic animals. Anat. Histol. Embryol. 11, 19-26.

11. Hong, S., Chang, Y. H., Han, S. H., Lee, J. B. (2005) Effect of full tendon transposition augmented with posterior intermuscular suture for paralytic strabismus. Am. J. Ophthal. 140, 477-483.

12. Horbańczuk, J. O. (2003) Struś afrykański. Auto-graf Sp.z.o.o. Warszawa

13. Kaczmarski, F. (1970) The fine structure of extraocular muscles of the tree sparrow, Passer montanus L. Zeit. Mikros.-Anatom For. 82, 523-536.

14. Kaczmarski, F. (1971) Classification of muscle fibers in the extraocular muscle of the bank vole (Clethrionomys glareolus, Schr.) and tree sparrow (Passer montanus, L.). Acta Med. Pol. 12, 173-176.

15. Kern, R. (1965) A comparative pharmacologic-histologic study of slow and twitch fibers in the superior rectus muscle of the rabbit. Invest. Ophthal. Vis. Scie. 4, 901-910.

16. Klećkowska-Nawrot, J. (2005) Morphology and development of the accessory organs of the eye of the pig in the foetal period. Acta Scient. Pol. 4, 121-140.

17. Klećkowska, J., Pospieszny, N. (2005) Morphological examination of the intraorbital muscles (musculi bulbi) in Persian cats in the perinatal period. Anat. Histol. Embryol. 34, 15-19.

18. Klećkowska, J., Janeczek, M., Wojnar, M., Pospieszny, N. (2006) Morphological examination of the introrbital muscles (musculi bulbi) in dogs in the perinatal period. Anat. Histol. Embryol. 35, 279-283.

19. Korzeniowska-Kromer, E. (1992) Development of the muscle spindles in the human fetal oblique muscles of the eyeball. Folia Morph. 51, 119-127.

20. Korzeniowska-Kromer, E. (1996) Morphologic features and number of muscle spindles in the oblique eye muscles of human fetuses. Folia Morph. 55, 341-342.

21. König, H. E., Korbel, R. (2016) Avian Anatomy Text book and Colour Atlas. 5m Publishing Ltd. UK.

22. Maier, A., Desantis, M., Eldred, E. (1971) Absence of muscle spindles in avian extraocular muscles. Exp. Eye Res. 12, 251-253.

23. Mcloon, L. K., Christiansen, S. P. (2003) Increasing extraocular muscle strength with insulin-like growth factor II. Invest. Ophthalmol. Vis. Sci. 44, 3866-3872.

24. Nickel, R., Schummer, A., Seiferle, E. (2004) Lehrbuch der Anatomie der Haustiere. Band V. Berlin and Hamburg: Verlag Paul Parey.

25. Noden, D. M., Marcucio, R., Borycki, A. G., Emerson, Jr C. P. (1999) Differentiation of avian craniofacial muscles: I. Patterns of early regulatory gene expression and myosin heavy chain synthesis. Dynam. 216, 96-112.

26. Nomina Anatomica Avium (1993) Second edition. Published by the Club. Cambridge Massachusetts.

27. Paul, A. C., Rosenthal, N. (2002) Different modes of hypertrophy in skeletal muscle fibers. J. Cell Biol. 18, 751-760.

28. Sohal, G. S., Sickles, D. W. (1986) Embryonic differentiation of fibre types in normal, paralysed and aneural avian superior oblique muscle. J. Embryol. Exp. Morphol. 96, 79-97.

29. Szarski, H. (1976) Anatomia porównawcza kręgowców. Państwowe Wydawnictwo Naukowe. Warszawa.

30. Wójtowicz-Kaczmarek, K. (1996) Morphometric features of recti muscles of the eye and their muscle spindles in human fetuses. Folia Morph. 55, 461-463.

31. Villarreal-Silva, E. E., Hinojosa Amaya, J. M., Bazaldua Cruz, J. J., Fernández, D. F., ElizondoOmaña, R. E., Guzmán López, S. (2013) A morphometric study of the extraocular muscles. Int. J. Morph. 31, 312-320. 